Session 1526

\title{
Development of a B.S.E. Concentration in Biomedical Engineering
}

\author{
Paul R. Leiffer, Roger V. Gonzalez \\ LeTourneau University
}

\begin{abstract}
A new program in Biomedical Engineering has been developed at LeTourneau University. Unlike most BME programs, this one is structured as one of five concentrations within a general engineering (B.S.E.) degree. Students receive a strong common core of mathematics, science, and engineering science courses, and then specialize in the final two years. Primary emphasis areas are in musculoskeletal biomechanics and biomedical instrumentation/signal processing. Development of the program entailed the establishment of (1) a series of specialized upper-level BME courses, (2) a BME laboratory capable of supporting basic experimentation and undergraduate research, (3) a BME capstone experience, (4) a BME summer internship experience, (5) guest workshops, and (6) a series of modules that fit within our core courses to facilitate "biomedical engineering across the curriculum." The first BME graduates will complete the program in May of 2004.
\end{abstract}

Introduction

For over twenty years, LeTourneau University has offered a Bachelor of Science in Engineering (B.S.E.) degree with electrical and mechanical concentrations, recently adding welding and computer engineering. Most of the courses taken in the first two years are common to all areas, with specialization in the final four semesters. In the fall of 2000, with the help of support from an NSF CCLI grant, we began a program in Biomedical Engineering as a fifth concentration within the B.S.E. Our goal was to offer a BME program with a strong interdisciplinary core, and, simultaneously, to make BME concepts available to all engineering students. Development of the curriculum and associated laboratories within the constraints of the degree became a type of exercise in engineering design.

In comparison with the BSE-BME program at Trinity College, which served as our model for the NSF grant, this program is also built upon a common core of courses but is fully multidisciplinary (as opposed to containing BSE-EE or BSE-ME stems). In addition, it currently includes a required internship experience and professional workshops with external collaborators.

Curriculum

The engineering curriculum at LeTourneau University consists of four elements: (1) a universitywide humanities-general education core, (2) an engineering core, (3) upper-level concentration 
courses, and (4) a capstone design experience. The BS in Engineering with a BME concentration parallels the four other programs in engineering offered at LeTourneau, with a basic common core and at least 35 hours for the concentration. The engineering core, taken by students in all concentrations, consists of the Calculus sequence, Chemistry, Physics, Graphics, Freshman Design, Manufacturing Processes, Computer Science, Statics, Dynamics, Circuits, Digital Electronics, Instrumentation Lab, Mechatronics, Thermodynamics, and Project Management. One advantage of having the freshman and sophomore years essentially common for all engineering students was that it gave us two years of lead time to develop the labs and upperlevel courses.

Twenty-four semester hours of specialized courses have been developed. Concentration courses have been prepared in Biomechanics, Musculoskeletal Biomechanics, Bioinstrumentation, and Biomedical Signal Processing. All of these courses have been made available as technical electives to all upper-class engineering students having the standard prerequisites. Courses in Biological Control Systems and Biomaterials Engineering are built upon existing courses in Fuzzy-Adaptive Controls and Materials Engineering. The final six hours consist of BME capstone design.

The curriculum provides a minimum of 16 hours of life science coursework, including laboratories. The life science coursework, which was already in place for the university's biology degree, consists of twelve hours of General \& Advanced Biology and eight hours of Human Anatomy and Physiology. These four courses provide students with a basic understanding of biological systems; they serve as the foundation for additional coursework necessary for students who desire to attend medical school or to pursue graduate work in BME. (Additional life science courses are available for those students who are following a pre-medical school plan in addition to BME, and should require only one additional semester of coursework, given appropriate planning.)

\section{Laboratory facilities}

A BME laboratory with two major areas, capable of supporting both classroom experiments and undergraduate research, has been established. Emphasis areas in the lab, coinciding with those in the curriculum, are biomechanics and biomedical signal processing.

The Biomedical Instrumentation and Signal Processing Laboratory accompanies the courses in Biomedical Signal Processing and Biological Control Systems. The purpose of this laboratory is to provide students with experience in signal acquisition, signal amplification, patient isolation and safety, and current techniques in computer processing of biological signals. Typical processing studied includes statistical signal techniques, analog and digital filtering, and spectral analysis. Control applications include various analog and digital simulation approaches to biological systems. The laboratory is equipped with 2 computer workstations with data acquisition capability, analog and digital oscilloscopes, a Biopac ${ }^{\mathrm{TM}}$ system for ECG, EMG, and EEG recording, and a variety of electrodes and biological transducers.

The Biomechanics-Motor Control Laboratory is used in conjunction with Introduction to Biomechanics and Musculoskeletal Biomechanics. This laboratory is also being used as an 
element to establish a biomechanics undergraduate research program. The laboratory is equipped to perform quantitative analysis of human movement. The hardware for the laboratory includes a floor-mounted force-plate, a Motion Analysis ${ }^{\mathrm{TM}}$ system with five high-speed cameras, Noraxon $^{\mathrm{TM}}$ EMG measurement equipment, and a PC interface system. Two multiprocessor workstations are available for robust computer graphic animation, computational musculoskeletal modeling, and quantitative analysis. Software has been purchased to perform standard gait analysis for student education and research. Students also benefit by graphical modeling and analysis of muscles, bones, and joints using SIMM (Software for Interactive Musculoskeletal Modeling).

Research

At most universities, only graduate students are able to participate in high level funded research. Students at LeTourneau University have had opportunities to take part in research as undergraduates. ${ }^{1}$ Three of the projects undertaken at our lab include the intelligent prosthetic arm (IPA) project, the anterior deficient knee (ACL-D) project, and the virtual environment project.

1. IPA Project: Until now prostheses had been strictly mechanical systems with little to crude end-user control capabilities. The IPA project involves acquiring electrical signals from individual muscles as a simulation of neural signals. These act as the control sequence to manipulate the artificial muscles of a model arm, allowing it to respond more like a natural part of the body.

2. ACL-D Project: Damage to the anterior cruciate ligament (ACL) is the most common knee injury for athletes and the general public. Our students are using the biomechanics laboratory in order to investigate why some individuals are able to function without their ACL. This knowledge could help us to understand how some can recover without the need for surgery, which could have a significant impact on the field of orthopedic medicine.

3. Virtual Environment Project: To validate our 3-dimensional musculoskeletal model of the knee, particularly to examine forces in the ligaments, we have developed a simulated virtual environment of the knee in dynamic loading conditions. This has been developed using a robotic set-up with a cadaver knee to measure joint contact and ligament forces given timevarying muscle and joint position.

Students in the BME program are required to take a one-hour research introduction course during both semesters of their junior year. This experience provides them with a preview of ongoing research projects at the university, introduces them to research techniques, and prepares them to be project team leaders in their senior year.

\section{Capstone Design}

Various biomedical research projects were part of our EE and ME capstone design for three years before the start of the BME program. The current two-semester BME capstone experience involves the design, development, and construction of the Intelligent Prosthetic Arm as a stepping-stone for the next generation of prosthetic limbs. The multidisciplinary nature of this 
project requires the interaction of students from the electrical, mechanical, and biomedical concentrations. An industry-based project management approach facilitates team roles, goalsetting, and communication. ${ }^{2}$

Internships

An undergraduate education in a specialized concentration must include the opportunity for students to receive a broad perspective of BME principles, research methods, and future career opportunities. To achieve this objective, external colleagues have been selected who will have a meaningful educational impact on students in the BME concentration through a required summer biomedical internship. Consequently, BME students planning to attend graduate school, medical school, or work in the medical device industry or in service organizations can be exposed to a wide range of career options before graduation.

\section{Workshops}

One or more BME workshops are presented annually at LeTourneau University for students in the concentration. These presentations are also open to other students, faculty, and the local medical community. Experts from various disciplines related to BME present material used to supplement the formal educational component of the program. Junior and senior level students participate in these workshops and complete additional assignments based on the material. Participation in at least two workshops is required for graduation.

Generally, visiting scholars come from collaborating institutions which provide summer internship opportunities. Workshops are designed to focus on topics outside of LeTourneau's BME curriculum, including such areas as rehabilitation engineering, laser-tissue interaction, and advances in medical imaging. Workshop presentations can also provide a service to the regional medical community. Guest workshops presented to date include Muscle Mechanics and Hydrocephalic Shunt Design.

\section{BME Modules}

A series of BME modules fit within several of our core engineering courses (including Circuits, Dynamics, Digital Electronics, and Mechatronics) in order to facilitate "biomedical engineering across the curriculum." 3 Modules concerning a biomedical application of the particular subject matter have been prepared for inclusion in several engineering courses to provide for increased integration of biomedical concepts throughout the entire curriculum. Every engineering student will be exposed to BME concepts and measurements and gain awareness of the importance of human considerations in all design. A mini-lecture with homework concerning BME applications is developed for core areas of engineering and made available for instructors at LeTourneau University, and elsewhere upon request. This approach serves to further integrate the engineering curriculum by means of a "BME concepts across the curriculum" approach.

Six modules have been completed and used in the following courses:

- Dynamics - Muscles forces across the elbow

- Circuits - Batteries for cardiac pacemakers 
- Thermodynamics - Bioenergetics: Heat transfer in the cell

- Fluid Mechanics - Introduction to hemodynamics: Blood flow dynamics

- Mechatronics - Control of prosthetic arms

- Digital Electronics - Digital-video analysis for single cardiac cells

An additional four modules are being developed:

- Statics - Static muscles across the elbow

- Digital Signal Processing - Signal averaging for evoked potentials

- Project management - Steps to FDA approval of medical devices

- Materials Engineering - Considerations in biomaterial selection

In addition, every engineering student learns the basics of electrocardiogram recording and processing through one particular experiment performed during the Instrumentation and Measurements Lab course, which is required in all engineering concentrations.

Results

Desired outcomes for the program (and results to date) are the following:

1. Graduates will have a strong background in biomedical measurements and biomechanics, experience with several key areas of biomedical equipment, and exposure to a wide range of medical and biological fields, all built on a strong core of engineering science and life sciences.

Result: One of LeTourneau's BME juniors qualified and interned last summer at the National Institutes of Health. Results of our seniors' performance on the Fundamentals of Engineering (F.E.) exam will be known in a few months.

2. Graduates will be prepared to complete rigorous engineering design projects for clients from industry, biomedical research, or the medical community.

Result: The Intelligent Prosthetic Arm project has involved students in a challenging capstone design project. Reporting on senior projects has earned our students three first place and one second place awards over the last four years in the ASME Regional Conference Oral Competition (Old Guard).

3. Graduates will be well-prepared for industry, graduate school, or, with the addition of six science courses, medical school.

Result: The initial class of BME students graduates in May of 2004. Most of them will be attending graduate school.

4. Laboratories and equipment specifically suited for the BME curriculum will allow the incorporation of undergraduate biomedical research on an on-going basis.

Result: In 2002, an NSF grant of almost $\$ 400,000$ was awarded to Dr. Gonzalez for research involving the Intelligent Prosthetic Arm. Several undergraduate students receive support from this research.

5. All students in engineering programs will be exposed to BME concepts. 
Result: Through the series of BME modules, the ECG experiment, and the possibility of participating in interdisciplinary senior design, all engineering students are interacting with biomedical concepts. Two of our ME graduates and one of our EE graduates now attend graduate school in Biomedical Engineering programs.

\section{Conclusions}

A unique program in Biomedical Engineering has been successfully established as a concentration within a general engineering degree. A comprehensive interdisciplinary engineering core curriculum is coupled with a specialized education in BME. The complex nature of the capstone design projects give students the experience of functioning in multidisciplinary teams. Students have the opportunity to participate in funded undergraduate research. Workshops and internships provide exposure to a wide range of BME research and design. Students completing this program gain a broad interdisciplinary knowledge, and students from other engineering areas benefit from exposure to BME concepts.

\section{Acknowledgements}

Partial support for this work was provided by the National Science Foundation's Course, Curriculum and Laboratory Improvement Program under grant DUE-0087898.

Bibliography

1. Gonzalez, R., Lopez,J., and Leiffer, P., "Is a Successful Research Laboratory Possible with Undergraduates Alone?," 2004 ASEE Conference Proceedings.

2. Gonzalez, R., "BME Undergraduate Design Projects Using Various Undergraduate Majors," 2001 ASEE Conference Proceedings.

3. Leiffer, P.and Gonzalez,R., "Development of Modules and Labs for 'Biomedical Engineering Across the Curriculum',” 2002 ASEE Conference Proceedings.

\section{PAUL R. LEIFFER, PhD,PE}

Dr. Leiffer is a professor in the School of Engineering and Engineering Technology at LeTourneau University, where he has taught since 1979. He received his M.S. and Ph.D. degrees in Biomedical Engineering from Drexel University. Prior to joining the faculty at LeTourneau, he was involved in cardiac cell research at the University of Kansas Medical Center. Email: paulleiffer@,letu.edu

ROGER V. GONZALEZ, PhD, PE

Is a professor of BME \& ME at LeTourneau University with specialties in Musculoskeletal Biomechanics and Dynamic Systems Modeling; Adjunct Professor in ME at University of Delaware; PE in Texas. He earned a BSME from UTEP and a MS and PhD in BME and ME, respectively, from UT Austin. He also was NIH-NRSA PostDoctoral Fellow at Northwestern Univ Med School, and the Rehab Inst of Chicago. Email: rogergonzalez@,letu.edu. 